The definitive version is available at http://www.blackwell-synergy.com/ DOI:10.1111/j.1399-3054.1994.tb02962.x About DOI 


\title{
Removal of nuclear contaminants and of non-specifically photosystem II-bound copper from photosystem II preparations
}

\author{
Juan B. Arellano, Wolfgang P. Schroder, Gerhard Sandmann, Ana Chueca and Matilde \\ Baron
}

In conventional photosystem II preparation high amounts of $\mathrm{Cu}$ are found. After fractionation by centrifugation, $\mathrm{Cu}$ can be completely removed from photosystem II without affecting either its photosynthetic activity or the composition of its specific proteins. We could demonstrate that the $\mathrm{Cu}$ was associated with nuclear contaminants in the starch fraction. Among the contaminants, several histones were identified by specific antisera and by N-terminal sequencing. In order to obtain homogeneous BBY preparations of PSII a procedure is employed that involves a $1000 \wedge^{\wedge}$ centrifugation step and which eliminates non-specifically bound metals, nucleic acids and histones with the starch pellet. The resulting starch-free BBY (BBY,_), which is free of these nuclear contaminants, is an appropriate preparation for biophysical studies or for those of metal interactions with PSII.

Key words - Copper, histones, pea, photosystem II, Pisum sativum, spinach, Spinacia oleracea.

J. B. Arellano, A. Chueca and M. Baron (corresponding author). Plant Biochemistry Dept, Estacion Experimental del Zaidín (CSIC), Profesor Alhareda I, E-18008 Gra-nada, Spain; W. P. Schroder, Dept of Biochemistry, Arrheniiis Laboratories for Natural Sciences, Stockholm Univ., S-10691, Stockholm, Sweden; G. Sandmann, Lehrstuhl f'iir Physiologic und Biochemie der Pflanzen, KonstaiK. Univ., 0-78464 KonstaiK. Germany.

\section{Introduction}

One of the events that have led to a better understanding of the primary steps involved in photosynthetic electron transport has been the development of isolation methods for the individual multienzyme complexes involved in such a process: photosystem II (PSII), the cytochrome $\mathrm{b}_{6} / \mathrm{f}$ complex and photosystem I (PSI).

Regarding PSII, different isolation procedures have been developed, based mostly on detergent solubilization (Berthold et al. 1981, Dunahay et al. 1984) but also on mechanical fractionation (Svensson and Albertsson 1989) of the thylakoid membrane. Nevertheless, to en-able comparison of the results reported by different groups, it is important to obtain standardized, highly purified preparations with the same protein constituents and mineral cot'actors such as manganese, copper and calcium. This is particularly important for sophisticated biophysical studies performed on PSII. The method de-scribed by Berthold et al (1981), the so-called BBY preparation, using Triton X100 , has become standard and is used extensively in biochemical and biophysical studies of PSII. However, regarding the Cu content (Droppa and Horvath 1990) and the polypeptide pattern of PSII in the 10 to $20 \mathrm{kDa}$ region (Baron ct al. 1990, Arellano et al. 1992), large variations have been reported. In a previous study we found that by differential centrifugation virtually all $\mathrm{Cu}$ could be removed (Baron et al. 1993). In this work we identity $\mathrm{Cu}$ in the photosystem II preparation as being associated with nuclear contaminants. Histones, nucleic acids and other metal ions are precipitated with starch upon centrifugation. Removal of these contaminants by introducing a starch centrifugation at $10000 \mathrm{~g}$, yielded highly active PSII, starch-free BBY particles (BBY s-) devoid of $\mathrm{Cu}$, and with improved optical properties. It is therefore suggested that $\mathrm{Cu}$ is not directly involved in oxygen evolution or in electron flow through PSII, and the BBY $\mathrm{s}_{\text {- }}$ preparation is thus the most appropiate for studies of metal interactions with PSII.

Abbreviations - BBY, PSII preparations isolated as described by Berthold et al. (1981); BBY $_{\mathrm{s}^{+}}$, starchcontaining BBY; $\mathrm{BBY}_{\mathrm{s}-\text {, }}$, starch-free BBY; $\mathrm{CP} 14, \mathrm{Chl} \mathrm{a} / \mathrm{b}$ binding polypeptide in PSII described by Irrgang et al. (1990); ELIPs, early light-inducible proteins; OEC, oxygen evolving complex; SF-proteins, polypeptides associated with the starch pellet in the BBY isolation process. 


\section{Materials and methods}

Pea plants (Pisum sativum L. cv. Lincoln) were grown hydroponically in Hewitt's full nutrient solution in a growth chamber for 4 weeks as described in Baron and Sandmann (1988). Spinach (Spinacia oleracea L.) was obtained from the local market.

BBY particles were prepared essentially according to Berthold et al. (1981) with the modifications of Ford and Evans (1983). BBY s- were obtained by adding a new step in the isolation method: after incubation of purified thylakoids with Triton X-100, the solution was centrifuged for 4 min at $10000 \mathrm{~g}$ to obtain a greenish-white starch pellet. The supernatant without starch was centrifuged at $40000 \mathrm{~g}$ for $25 \mathrm{~min}$ and the PSII particle-containing pellet resuspended in $50 \mathrm{mM}$, MES, pH 6.5, 5 $\mathrm{mM} \mathrm{MgCI} 2,15 \mathrm{mM} \mathrm{NaCI}$ and $400 \mathrm{mM}$ sucrose (stock buffer). To obtain $\mathrm{BBY}_{\mathrm{s}^{+}}$preparations, the centrifugation step at $10000 \mathrm{~g}$ after Triton X-100 treatment was omitted. In both cases, excess detergent was removed from the PSII particles by washing twice with the stock buffer. For the study of contaminants, the starch pellet was washed $3 \mathrm{x}$ with stock buffer, centrifuging for 5 min at $5000 \mathrm{~g}$ each time. Particles devoid of polypeptides from the oxygen evolving complex (OEC) were obtained by washing as described in Ljungberg et al. (1986).

Sodium dodecyl sulphate-polyacrylamide gel electro-phoresis (SDS-PAGE) was carried out on $17.5 \%$ polyacrylamide gels containing $4 \mathrm{M}$ urea, as described by Laemmli (1970).

For raising antisera against the proteins present in the starch fraction, the proteins were isolated by cutting the stained protein bands from SDS-polyacrylamide slab gels, and eluting the slices by electrodialysis. About $10 \mu \mathrm{g}$ of each protein was used for immunizing mice, using standard immunological procedures (Fraser et al. 1992). Western blots were performed as in Towbin et al. (1984), and the antigen-antibody complex was developed by a peroxidase-conjugated goatantimouse serum. Antibodies against the starch fraction proteins and ELIPs (early-light-inducible proteins; Cronshagen and Herzfeld 1990) were obtained for pea. The antisera against OEC proteins, CP 14 (Irrgang et al. 1990), phosphoprotein and the $10 \mathrm{kDa}$ protein described by Ljungberg et al. (1986), were raised from spinach proteins. Histone antisera were against animal histones.

For N-terminal sequencing, proteins were isolated by SDS-PAGE under the above conditions without urea, and transferred to a polyvinylidene difluoride membrane (PVDF, Millipore) using a JKA-Biotech (Bedford, USA) semidry electroblotter. After Coomassie staining of the PVDF membrane, protein bands were excised and se-quenced on an Applied Biosystem (La Jolla, CA, USA) model 470 Sequenator.

The isolation of DNA fragments by electrophoresis in $0.3 \%$ agarose gels, has been described by Sambrook et al. (1989). Nucleic acid concentration was spectrophotomet-rically determined at 260 $\mathrm{nm}$. The absorbance ratio A261/A280 was also measured to identify protein contam-ination.

The metal content was determined by atomic absorp-tion spectrometry (Perkin-Elmer model 503), using a hollow cathode lamp and a graphite furnace (Perkin-Elmer HGA-400; Uberlingen, Germany) (Arellano et al. 1993).

\section{Results}

Polypeptide patterns of thylakoid membranes, $\mathrm{BBY}_{\mathrm{s}^{+}}$and $\mathrm{BBY}_{\mathrm{s}-}$ and the starch pellet of the $\mathrm{BBY}_{\mathrm{s}-}$ isolation, both from spinach (lanes 1-4) and pea (lanes 7-10), are shown in Fig. 1. Pea and spinach extrinsic 16, 23 and $33 \mathrm{kDa}$ proteins related to the OEC were applied as reference proteins in lanes 5 and 6. They were obtained from the supernatant of Nad-treated PSII particles. Higher migra-tion rates of the extrinsic 16 and $23 \mathrm{kDa}$ proteins for pea, as compared to spinach, were noted. This means a lower apparent molecular mass of the former. It is seen that pea BBY,, (lane 8) is depleted of 4 polypeptides of apparent molecular masses of ca 12, 17, 19 and $20 \mathrm{kDa}$. The missing polypeptides appear in the starch traction pellet resulting from the $10000 \mathrm{~g}$ centrifugation step (lane 7). Parallel results were. obtained with spinach, with starch fraction proteins (SF-proteins) within the same molecular mass range. The identity of SF-proteins of both species was demonstrated by means of cross reactivity with the corresponding antisera (data not shown). The weakly-stained 
polypeptides which appear between 12 and $17 \mathrm{kDa}$ in the pea starch fraction, are easily removed by washing of the starch pellet as described in Materials and methods. It appears that in spinach BBY,", preparations, only 3 polypeptides are lost by starch removal. However, we found by immunodetection that the $20 \mathrm{kDa}$ SF-protein in spinach BBY..+ comigrates with the OEC $16 \mathrm{kDa}$ pro-tein (Fig. 2). We carried out western blotting with differ-ent spinach preparations: isolated thylakoids (lanes 1 and 10), BBY,+ (lanes 2, 9), BBY,. (lanes 3, 8), starch pellet fraction (lanes 4, 7) and the supernatant from NaSCN/ Triton X-100 treated BBY.,- (lanes 5, 6). After transfer to/^ nitrocellulose, lanes 1 to 5 were stained with Ponceau red and lanes 6 to 10 were treated with a specific antiserum against the OEC $16 \mathrm{kDa}$ protein. A positive immunoreactive band was detected in lanes 10, 9, 8 and 6, corresponding to spinach thylakoids, BBYs,$+ \mathrm{BBY}$, and the supernatant from Triton NaSCN-treated BBY,-, respec lively. The latter treatment solubilizes the OEC polypeptides, including the 10 and $22 \mathrm{kDa}$ proteins (Ljungberg et al. 1986). It is pointed out that cross reactivity with the SF-proteins was not observed.

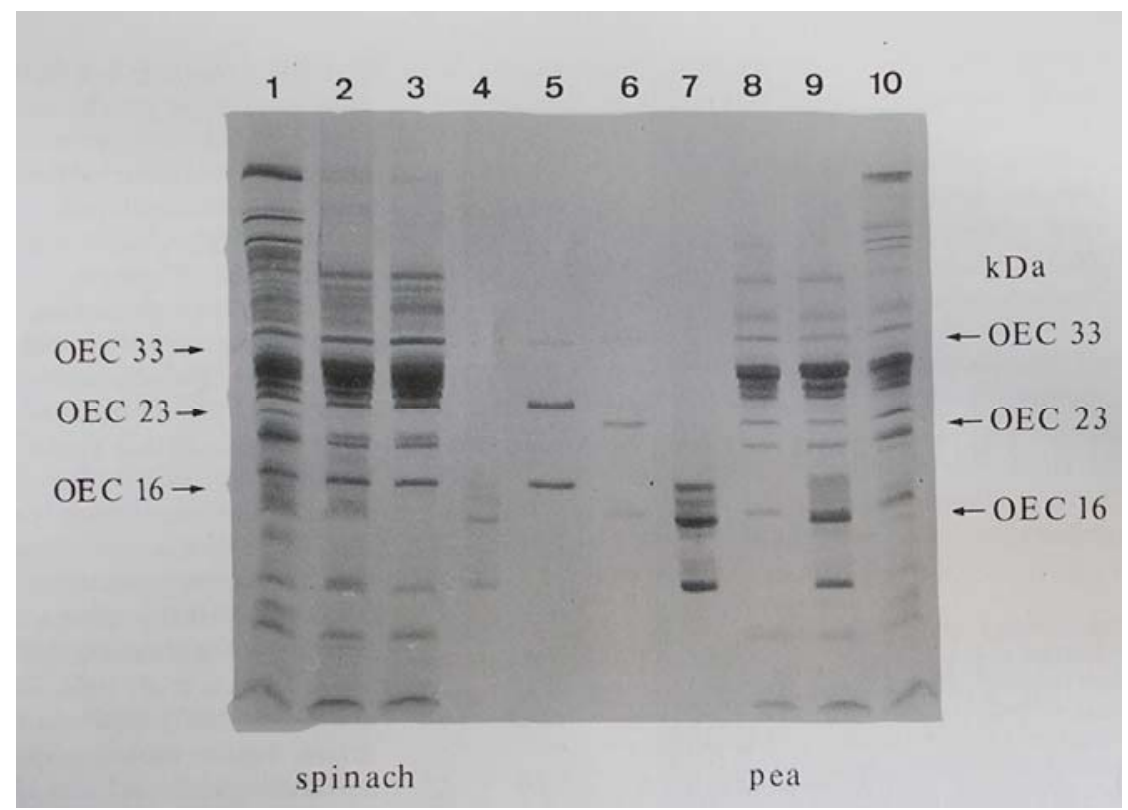

Fig1 SDS-4 $M$ urea PAGE of Thylakoids $(1,10), \mathrm{BBY}_{\mathrm{s}+}(2,9)$, BBY $_{\mathrm{s}-}(3,8)$, starch pellet $(4,7)$ and the supernatant from $\mathrm{NaCl}$ - treated $\mathrm{BBY}_{\mathrm{s}-}$ $(5,6)$

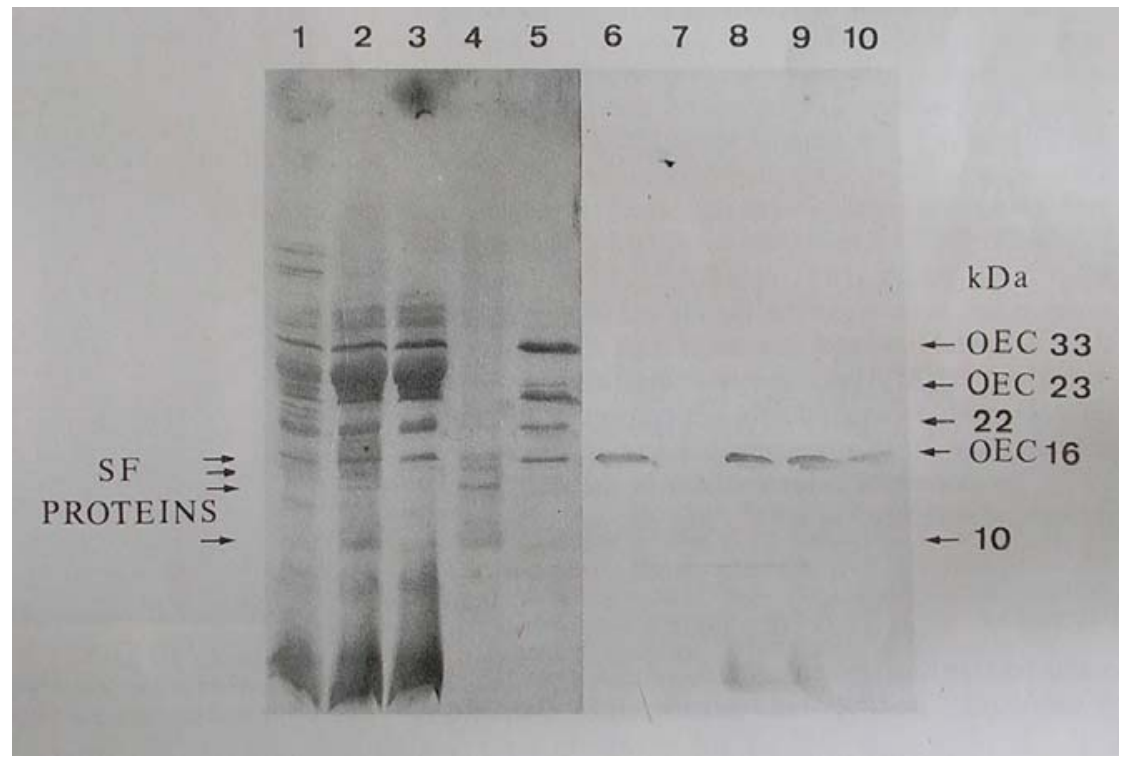

Fig. 2. Reactivity of the antibody against OEC $16 \mathrm{kDa}$ protein with blotted samples (lanes 6-10), blotted proteins bands stained by Ponceau red (lanes 1-5).

Spinach samples of thylakoids $(1,10), \mathrm{BBY}_{\mathrm{s}+}(2,9), \mathrm{BBY}_{\mathrm{s}-}$ $(3,8)$, starch fraction $(4,7)$ and the supernatant from NaSCN/Triton-Treated BBY s$(5,6)$ 
To characterize the 4 proteins that appear in the starch traction, we raised different antibodies against PSII proteins with molecular masses in the 10-20 kDa range. Antisera against CP 14 apoprotein, $10 \mathrm{kDa}$ phosphoprotein, the $10 \mathrm{kDa}$ protein described by Ljungberg et al. (1986) and the ELIPs, did not show cross-reactivity with the starch-associated proteins from pea or spinach by immunoelectrophoresis. In addition, we carried out west-ern blotting experiments with antisera

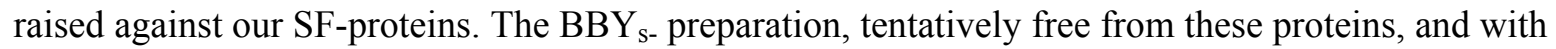
good PSII-related activity, gave no immunoreactive bands, indicating that our polypep-tides were neither PSII proteins nor their degradation products. For the identification of the starch-associated proteins, we tried to determine their N-terminal sequence. Unfortunately, 3 of the proteins were Nterminally blocked. Thus, it was possible to obtain only the sequence of the $17 \mathrm{kDa}$ protein: AlaArg-Tre-Lys-Gln. Comparing with homologous proteins in the GenBank Swiss-Prot, we found that our protein was identical to histone $\mathrm{H} 3$ from plants, fungi, yeast and humans.

The results prompted us to test the identity of the other SF-proteins with histone antibodies. Western blot analysis with antibodies against animal histones confirmed the identity of the sequenced protein and identified SF 20 and SF 19 as H2 histones, and SF 12 as histone H4. Figure 3 shows that in the starch fraction from spinach, the antiserum against H2b cross-reacted with SF 20 and SF 19, whereas the antiserum against H4 reacted with SF 12 and had a secondary reaction with the SF $17 \mathrm{kDa}$ polypeptide.

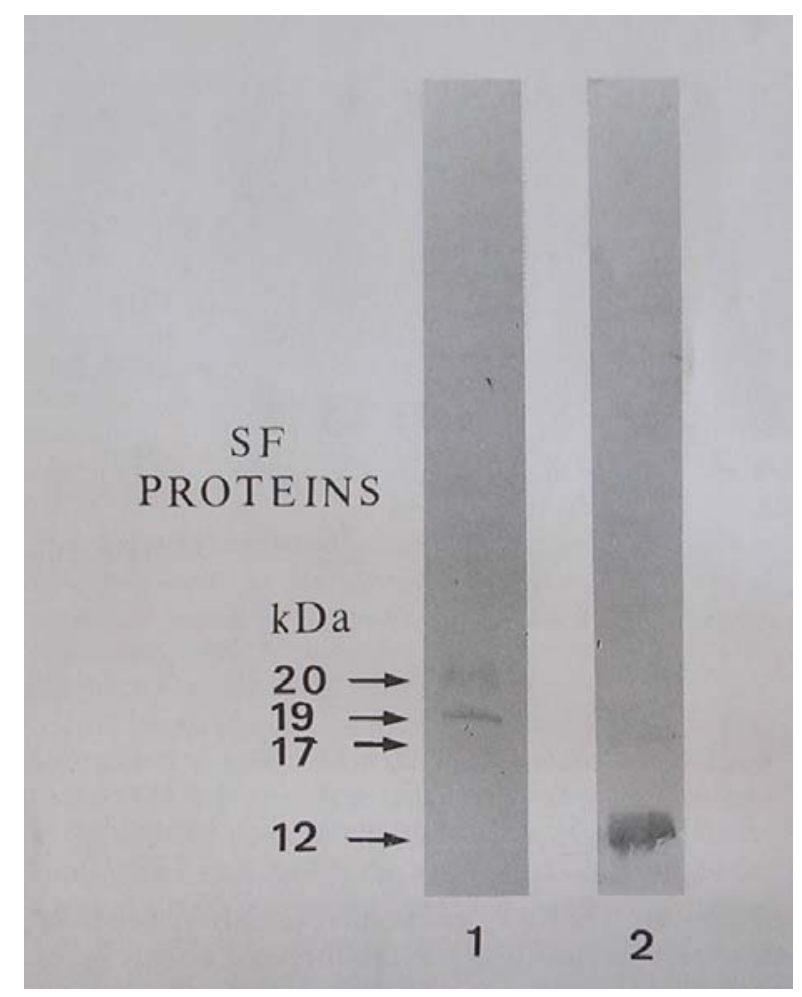

Fig. 3. Inmunoblotting of a pea starch fraction using antibodies against animal histones $\mathrm{H} 2 \mathrm{~b}(1)$ and $\mathrm{H} 4$ (2).

The identification of the histones in the usual BBY preparation $\left(\mathrm{BBY}_{\mathrm{s}+}\right)$ raised the question as to whether or not they were associated with DNA. We therefore deter-mined the nucleic acid content of spinach $\mathrm{BBY}_{\mathrm{s}^{+}}$and $\mathrm{BBY}_{\mathrm{s}-}$ particles, and found it to be 150 and $20\left(\mu \mathrm{g} \mathrm{mg}^{-1} \mathrm{Chl}\right.$, respectively. A large amount of nucleic acids (DNA and RNA) was found in $\mathrm{BBY}_{\mathrm{s}^{+}}$, which was decreased 7.5-fold in $\mathrm{BBY}_{\mathrm{s}-\text {. }}$ The separation of DNA fragments and RNA from spinach $\mathrm{BBY}_{\mathrm{s}^{+}}$and $\mathrm{BBY}_{\mathrm{s}-\text {, }}$ as well as 
in the starch pellet, is shown in the agarose gel of Fig. 4. BBY $\mathrm{s}_{+}$(lane 1) contains a large amount af high-size DNA fragments and RNA. These decrease drastically in $\mathrm{BBY}_{\mathrm{s}-}$ (lane 2), with a concomitant high content in the starch fraction (lane 3). In a previous publication (Baron et al.

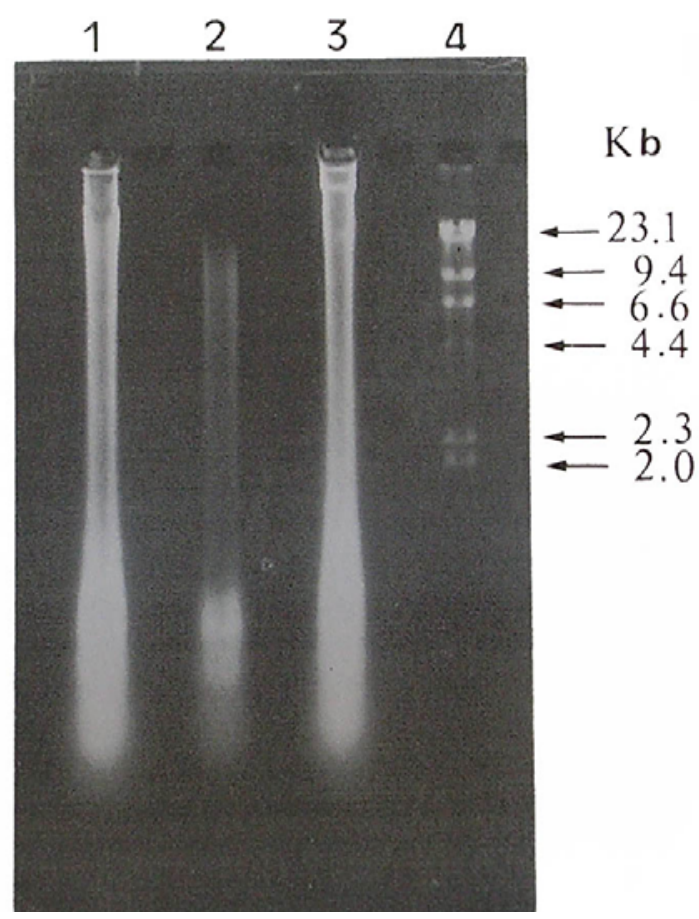

Fig. 4. Agarose gel analysis of spinach $\mathrm{BBY}_{\mathrm{s}^{+}}(1)$, $\mathrm{BBY}_{\mathrm{s}-}(2)$, starch fraction (3) and Phage $\lambda$ digested with Hind III as marker (4)

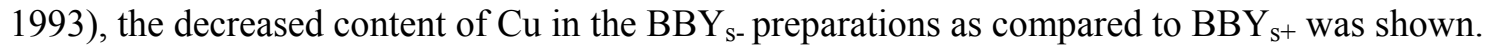

\section{Discussion}

A standard method for preparation of PSII particles, the so-called BBY particles, was introduced by Berthold et al. (1981), resulting in a PSII complex being obtained of high yield with a high oxygenevolving ability. In the course of our work on the binding of $\mathrm{Cu}$ to this prep-aration, we observed that after a $10000 \mathrm{~g}$ centrifugation to remove starch the pellet also contained high amounts of DNA, RNA, $\mathrm{Cu}$ and 4 polypeptides of ca 12,17, 19 and $20 \mathrm{kDa}$ (SF-proteins). The resulting PSI1 particles, free from these contaminants, were called $\mathrm{BBY}_{\mathrm{s} \text {. }}$ By using immunological methods and after protein sequencing of one of these proteins, it could be demonstratet that SF-12, 17, 19 and 20 $\mathrm{kDa}$ were not PSI1 proteins, but were histones closely related to histones H2, H3 and H4 (Spiker 1982, Spiker 1985). Centrifugation at lower than $10000 \mathrm{~g}$ did not completely remove these contamination proteins. There is a progressive decrease of $\mathrm{Cu}$ content and SF-proteins following centrifugation at $1000 \mathrm{~g}, 3000 \mathrm{~g}$ or $5000 \mathrm{~g}$, (Baron et al. 1993). The different procedures for obtaining BBY particles (Ford and Evans 1983, Droppa et al. 1984, Dunahay et al. 1984, Sibbald and Green 1987) either do not all include the centrifu-gation step for removing starch or are performed at in-sufficient speed.

Thylakoid membranes obtained by differential centrifugation are usually contaminated by nuclear fragments (Hoyer-Hansen and Simpson 1977, Welty et al. 1992). Such preparations are commonly used for BBY isolation without previous purification. Our present work shows that nuclear 
contaminations are found in the conventional BBY preparations used in most studies of PSII. Morever, the histones found in these preparations produce a false PSII polypeptide pattern, and in some cases the histones even comigrate with functional PSII proteins (e.g. SF 20 with OEC 16, Figs 1 and 2). Some authors have isolated BBY particles using low speed centrifugation for starch removal $\left(1000\right.$ or $3500 \mathrm{~g}$ ), but our results demonstrate that $\mathrm{BBY}_{\mathrm{s}-}$ can only be obtained after centrifugation at $10000 \mathrm{~g}$ which removes not only starch, but also histones and DNA. If, according to Welty et al. (1992), the his-tones are maintained in a chromatin structure during preparation of the thylakoids, they would pellet after the Triton X-100 treatment at the centrifugal force in question.

As regards the high metal content of the starch-histone contaminated $\mathrm{BBY}_{\mathrm{s}+}$ particles, the bulk of

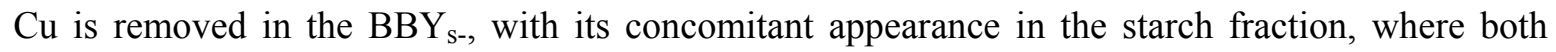
histones and nucleic acids are present. We have found high amounts of $\mathrm{Ca}, \mathrm{Fe}$ and $\mathrm{Zn}$ in the starch pellet (data not shown), which may contam-inate the $\mathrm{BBY}_{\mathrm{s}+}$ preparation.

Among the authors who have described the presence of metals in cell nuclei bound to nuclear proteins and/or nucleic acids are Lebkowski and Laemli (1982a,b). Fe, Cu, Mg and $\mathrm{Zn}$ have been detected in situ in the nucleus of animal cells by X-ray microanalysis or by X-ray fluo-rescence analysis of a native chromosomal DNA-protein complex (Skrinska et al. 1978, Quintana et al. 1987). The phosphate groups as well as the purine and pyrimidine bases of the nucleic acids offer a large number of binding sites for metal ions (Eichhorn et al. 1971). Moreover, metals like $\mathrm{Cu}$ and Ca could be involved in the reversible process of DNA folding (Lebkowski and Laemli 1982a,b).

Based on the present results, we propose that the $\mathrm{Cu}$ found in the $\mathrm{BBY}_{\mathrm{s}+}$ preparation is a nuclear contamination. It can easily be removed from the PSII complex by removal of starch, a treatment that exerts no negative effect on the oxygen-evolving activity (Baron et al. 1983) and thus suggesting that this metal is not directly in-volved in oxygen evolution. Consequently, several reports (Droppa et al. 1984, Ono et al. 1984, Sibbald and Green 1987, Droppa and Horvath 1990, Arvidsson et al. 1992) on the association of $\mathrm{Cu}$ with PSII need to be reevaluated. Manganese, a metal directly involved in ox-ygen evolution, remains bound to the PSII complex. Binding of other metal ions to PSII may also have to be re-examined as a result of possible contamination by DNA and histones. The use of a preparation similar to our $\mathrm{BBY}_{\mathrm{s}-}$ may be necessary to obtain reliable results concerning the interaction of metals with PSII.

Our notion that the $\mathrm{Cu}$ found in $\mathrm{BBY}_{\mathrm{s}^{+}}$cannot have another origin, for example $\mathrm{Cu}$-binding proteins in the chloroplast or cytosol, is based on previous observations (Baron et al. 1993). We demonstrated that these proteins were removed during the first steps of the PSII isolation process, with a parallel decrease in $\mathrm{Cu}$.

The introduction of the $10000 \mathrm{~g}$ centrifugation step with the concomitant removal of starch, nucleic acids and histones, also changes the optical properties of the BBY particles: transmittance at 830 $\mathrm{nm}$ is increased (data not shown) as a consequence of lesser aggregation of the samples.

The method for removing nuclear contamination from PSII preparations also has the advantage of not reducing the preparative yield and not prolonging isolation. Other means of eliminating impurities, such as the use of chloroplasts purified by a discontinuous sucrose gradient, involve excessive time and effort.

In conclusion, the simple modification proposed for the BBY procedure for the isolation of PSII particles, which involves an additional centrifugation for $4 \mathrm{~min}$ at $10000 \mathrm{~g}$ after Triton treatment, increases the purity of PSII. The resulting $\mathrm{BBY}_{\mathrm{s}-}$ particles are a highly purified PSII preparation, which is of advantage for metal binding studies and for biophysical studies on PSII.

Acknowledgments - This work was supported by a grant from the Spanish DGICYT (Project PB 88-0092) and a Spanish-German Exchange Program (MEC-DAAD). J. B. Arellano was the recipient of a predoctoral fellowship from the Spanish Science and Education Ministry. Thanks are due to Junta de Andalucía and the Margit and Foike Pehrzon Foundation for financing W. P. Schroder's and J. B. Arellano's stays in Granada and Stockholm, respectively. The authors are very 
grateful to Prof. Dr Lopez Gorge and Prof. Dr Peter Böger for helpful discussions and to Mrs F. Castro for skilful technical assistance. Histone and CP 14 antibodies were generous gifts from Dr S. Muller (CNRS, Strasbourg, France) and Dr K. Irrgang (Max Volmer Institut, Berlin Univ., Germany).

\section{References}

Arellano, J. B., Baron, M., Schröder, W., Sandmann, G., Chueca, A. \& Lopez Gorge, J. 1992. The ambiguous role of $\mathrm{Cu}$ in photosystem II. - In Research in Photosynthesis (N. Murata, ed.), Vol. 2, pp. 105-108. Kluwer Academic Pub-lishers, Dordrecht. ISBN 0-7923-2090-3.

- , Baron, M., Chueca, A. \& Lachica, M. 1993. Analytical determination of $\mathrm{Cu}$ in different chloroplast preparations. - Plant Soil 154: 7-11.

Arvidsson, P. O., Bratt, C. E., Andréasson, L. E. \& Akerlund H. E. 1992. Copper present in PSII is associated with CP26. - In Research in Photosynthesis (N. Murata, ed.). Vol. I, pp. 235-238. Kluwer Academic Publishers, Dordrecht. ISBN 0-7293-2090-5.

Baron, M. \& Sandmann, G. 1988. Activities of Cu-containing proteins in Cu-depleted pea leaves. Physiol. Plant. 72: 801-806.

- , Lachica, M., Chueca, A. \& Sandmann. G. 1990. The role ot $\mathrm{Cu}$ in the structural organization of PSII membrane. - In Current Research in Photosynthesis (M. Baltscheffsky, ed.), Vol 1 pp. 303306. Kluwer Academic Publishers, Dor-drecht. ISBN 0-7923-0588-4.

- , Arellano, J. B., Schroder, W., Lachica, M. \& Chueca, A. 1993. Copper binding sites associated with photosystem II preparations. - Photosynthetica 28: 195-204.

Berthold, D. A., Backock, G. T. \& Yocum, C. F. 1981. A highly resolved oxygen-evolving photosystem II preparation from spinach thylakoid membranes. - FEBS Lett. 134: 231-234.

Cronshagen, U. \& Herzfeld, F. 1990. Distribution of the early-light inducible protein in the thylakoids of developing pea chloroplasts. - Eur. J. Biochem. 193: 361-366.

Droppa, M. \& Horvath, G. 1990. The role ol'Cu in photosynthe-sis. - Crit. Rev. Plant Sci. 9: 111123.

- , Terry, N. \& Horvath, G. 1984. Effects of copper deficiency on photosynthetic electron transport.Proc. Natl. Acad. Sci. USA 81: 2369-2373.

Dunahay, T. D., Staehelin, L. A., Seibert, M., Ogilvie, P. D. \& Berg, S. P. 1984. Structural, biochemical and biophysical characterization of four oxygen-evolving photosystem II preparations from spinach. - Biochim Biophys. Acta 764: 179-193.

Eichhorn, G. L., Berger, N. A., Buttzow, J. J., dark. P., Rifkind, J.M.,Shin,Y.A. \& Tarien, E. 1971. The effect of metal ions on the stucture of nucleic acids. - Adv. Chem. 100: 135- 154.

Ford, R. C. \& Evans, M. C. W. 1983. Isolation of a PSII preparation from higher plants with highly enriched oxygen-evolving activity. - FEBS Lett. 160: 159-164.

Fraser, P. D., Misawa, N., Linden, H., Yan-iano, S., Kobayashi, K. \& Sandmann, G. 1992. Expression in Escherichia coli, purification and reactivation of the recombinant Erwinia uredovora phytoene desaturase. - J. Biol. Chem. 267: 19891-19895.

Hoyer-Hansen, G. \& Simpson, D. J. 1977. Changes in the polypeptide composition of internal membranes of barley plastids during greening. - Carlsberg Res. Commun. 42:379-389.

Irrgang, K. D., Bechtel, C., Vater, J. \& Renger, G. 1990. A new Chl alb binding protein in photosystem II from spinach with a M, of $14 \mathrm{kDa}$. - In Current Research in Photosynthesis (M. Baltscheffsky, ed.). Vol. 1, pp. 355-358. Kluwer Academic Publishers, Dordrecht. ISBN 0-79230588-4.

Laemmli, U. K. 1970. Cleavage of structural proteins during the assembly of the head of bacteriophage T4. - Nature 227: 680-685.

Lebkowski, J. S. \& Laemmli, U. K. 1982a. Evidence for two levels of DNA folding in histonedepleted HeLa interphase nuclei. - J. Mol. Biol. 156: 309-324.

- \& Laemmli, U. K. 1982b. Non histone-proteins and long-range organization of HeLa interphase DNA. - J. Mol. Biol. 156: 325-344.

Ljungberg, U., Akerlund, H.-E. \& Anderson, B. 1986. Isolation and characterization of the $10 \mathrm{kDa}$ 
and $22 \mathrm{kDa}$ polypeptides from higher plant photosystem II. - Eur. J. Biochem. 158: 477-482.

Ono, T, Nakatani, H. Y, Johnson, E., Arntzen, C. J. \& Inoue, Y. 1984. Comparative biochemical properties of oxygen evolving photosystem II particles and of chloroplasts isolated from intermittently flashed wheat leaves. - In Advances in Photosynthesis Research (C. Sybesma, ed.). Vol. 1, pp. 383-386. Martinus Nijhoff/Dr W. Junk Publishers, The Hague. ISBN 90-2472946-7.

Quintana, C., Olmedilla, A., Antoine, N. \& Carizqueta, A. 1987. The ocurrence of metals Al, Fe Ni, $\mathrm{Cu}, \mathrm{Zn}$ in the nuclei of animal cells: an ultrastructural, in situ. X-ray microanalytical study.-Biol. Cell 61: 115-119.

Sambrook, J., Fritsch, E. F. \& Maniatis, T. 1989. Properties of nucleic acids. - In Molecular Cloning: A Laboratory Manual (C Nolan, ed.). Appendix C, p. 1. Cold Spring Harbor Laboratory, Cold Spring Harbor, NY. ISBN 0-87969-309-6. Sibbald, P. R. \& Green, B. R. 1987. Copper in PSII. Association with LHCII. - Photosynth. Res. 14: 201-209.

Skrinska, V. A., Messineo, L., Towns, R. L. R. \& Pearson, K. H.1978. Transition metals in calfthymus deoxirybonucleopro-tein. - Experientia 34: 15-17.

Spiker, S. 1982. Histone variants in plants: Evidence for primary structure variants differing in molecular weight. - J. Biol. Chem. 257: 14250-14255.

- 1985.Plant chromatine structure. - Annu. Rev. Plant Phy-siol. 36: 235-253.

Svensson, P. \& Albertsson, P.-A. 1989. Preparation of highly enriched photosystem II membrane vesicles by a nonde-tergent method. - Photosynth. Res. 20: 249-259.

Towbin, L., Staehelin, T. \& Gordon, J. 1984. Electrophoretic transfer of proteins from polyacrylamide gels to nitrocellu-lose sheets: Procedure and some applications. - Proc. Natl. Acad. Sci. USA 76: 4350-4354.

Welty, B. A., Morishige, D. T. \& Thornber, J. P. 1992. Identity of a group of $13.5-20 \mathrm{kDa}$ polypeptides whose apparent abundance decrease during plastid development. - Plant Cell Physiol. 33: 1049-1055. 